PLEASE NOTE! THIS IS SELF-ARCHIVED VERSION OF THE ORIGINAL ARTICLE

To cite this Article: P. Marjanen, O. Ojajärvi, S. Kumar, A. Kumar (2018) GAME FOR CHILDREN TO SUPPORT SOCIAL SKILLS, INTED2018 Proceedings, pp. 3354-3362

doi: $10.21125 /$ inted.2018.0647

URL: https://library.iated.org/view/MARJANEN2018GAM 


\title{
GAME FOR CHILDREN TO SUPPORT SOCIAL SKILLS
}

\author{
Paivi Marjanen ${ }^{1}$, Olli Ojajärvi², Shubham Kumar ${ }^{3}$, Amit Kumar ${ }^{4}$ \\ ${ }^{1}$ Laurea University of Applied sciences (Finland) \\ ${ }^{2}$ Laurea University of Applied sciences (Finland) \\ ${ }^{3}$ Kalinga Institute of Industrial Technology (India) \\ ${ }^{4}$ Kalinga Institute of Industrial Technology (India)
}

\begin{abstract}
Children learn social and emotional skills from their peers, parents and people with whom they are in contact. According to Vygotsky sociocultural peer group learning is a result of children's co-operation and interpretive reproduction. Good peer group learning session gives the children possibility for the social comparison. It builds also self-perception and includes action and many time some artifacts.

Children can learn in peer groups by playing games. Digitalization also is a vital part of daily living and learning environments are dramatically changing. Under these arguments rouse an idea to develop a game that will meet the match. A new game where children can learn in groups. Other demands were that it should be easily grasped, it is cheap and it would work globally not depending on the cultural backgrounds of the players. One important point was that new elements could be added to the game depending on the amount of digital technology it is possible to use, but it should also work without any technology as a board game.

Hence, based on data collected from India and Finland, a thorough analysis was done. Furthermore based on the analysis, a digitalized interface was created which would act as a digital assistant for the actual game. The interface does not contains the game in itself but acts as an assistant, for the game to be played smoothly and effortlessly.

The aim of the article is to present a new prototype of game which emphasizes on supporting children's social skills. The game would be developed as a part of FINDIgATE project. FINDIgATE is a CIMO funded project that does an India - Finland cooperation with Laurea University of Applied Science, Turku University in Finland and two universities KIIT in Bhubaneswar and IIT in Kanpur and Loyola College in Chennai. Developing and testing of the game happened in international and interdisciplinary Indian-Finnish team. The designing process based on the user-based development, and the main users were the children themselves.
\end{abstract}

Keywords: Digitalization, Education, Gamification, Game Based Learning, Socio-cultural learning, User-Based Development

\section{$1 \quad$ INTRODUCTION}

In this article is presented pedagogical prototype process of the game which main aim is to support social skills of a child. The idea of the game was developed by using user-centric approach by employing service design methods. Game is still in a developing stage and the design process is still going on. The rules, format and platform of the game was decided after going through an intensive procedure of data collection and methodological research which was conducted in two countries for a period of seven months. At the end of the procedure an overall skeleton of the game was developed and the scope of further expansion in terms of digitalization and cross-platform development were discussed upon.

The whole structure of the design process relive upon three underlying pillars namely Peer Group 
Learning, Game Based Learning and Gamification. Important aspects of education and well-being of children were imbibed from sections into the game. We started up with an existing game and modified it on a new game. The aim of the game is that it will be playable in materials that are easy to find globally and are very cheap, and in internet there will be published a portal that provides a platform for the game manuals and applications. The game would work in different platforms in a board game version when there's very little technology like in developing countries in rural areas and add digital elements to it when there is more technology available. At the same time the game should be easily grasped and work globally not depending on the cultural background of the players.

The prototype has been developed in international and interdisciplinary Indian-Finnish team. The designing process has been developed as a part of a FINDIgATE project. FINDIgATE is a CIMO funded project that does a India - Finland cooperation with Laurea University of Applied Science and Turku University in Finland and two universities in India KIIT in Bhubaneswar and IIT in Kanpur and Loyola College in Chennai. Data of this game design has been collected in Jharsuguda and in Bhubaneswar in India.

\section{SOCIOCULTURAL PEER GROUP LEARNING}

Sociocultural theory based on the ideas of Vygotsky in the early 1900s. Theory focus on social interaction. The child is considered an active agent who learns through acting. Vygotsky [1] points out that children learn more advanced knowledge and skills in the same way as the adults do. Awareness of learning is an internal evolutionary process, which is only possible when children interact in their own environment and work with their peers. Once these processes are internalized, they become part of the child's development. Vygotsky also stressed, that a child has a need to play. Playing is a means to satisfy the needs related to a small child's life.

Collaborative, peer group learning consists of shared goals, commitment, evaluation of the actions and shared understanding. This is the way how a child can build meanings. Collaborative learning can create a new kind of knowledge and different results and outputs. Lehtinen [2] states that children's daily experiences with other children either encourage or discourage the development of their different skills. Peer relations are an important learning opportunity. In peer relations children can learn social skills, empathy and the ability to stand the second position. Peer group work is an essential part of children's everyday life and social identity and the building of skills needed in the future. In peer relations children investigate the activities and social environment of the adults. They also test their own abilities. Children create friendships, consult each other, work and play together. At the same time peer relations are emotionally important. Having fun with other children they can share secrets and overcome anxieties. Movement and activities are also the heart of learning [3].

Sociocultural perspective for learning stresses the role and meaning of peer interaction in a learning process. Many studies show the effective role of playing in learning process [4]. The child is considered an active agent who learns through actions. Good learning positions are situations, in which a child defines a problem, tests different solutions to it by himself or together with his/her peers and finally comes to a conclusion through action. In peer group learning situations, children are not offered readymade solutions, even if the teacher has a guiding role in the learning process. [5].The peer learning essentially refers to children's learning with and from each other as fellow learners without any implied authority to any individual, based on the tenet that children learn a great deal by explaining their ideas to others and by participating in activities in which they can learn from their peers.

Peer groups play an important role in socialization, especially in childhood and adolescence. Peer groups are the only form of socialization that is not under the control of adults. Peer groups provide children with the opportunity to be a part of relationships that are productive and beneficial for all parties involved. They also allow children to create relationships with one another without being under adult control. [6] Studies have shown that an adult-led teaching style leads to a problem that children do not learn as much as they should learn with peers to whom the content is not taught directly but through playfulness [7].

Working in a peer group also teaches children to tolerate others' criticisms. Peer relations have an important role in children's learning and they are an integral part of children's everyday life. Children can also test their skills in peer groups all group situations are possibilities to create friendships, play and negotiate together. At the same time, peer relationships are emotionally important. [8] Peer groups foster also self-exploration. Children begin to make decisions for themselves and participate in activities 
that allow them to express who they are. Children are also able to experience and work through conflicts with their peers, cooperate with each other, and compete with each other in peer groups.

In peer group learning situations children have possibility to train their self-directed learning skills and thus lays the foundation for lifelong continuing self-education. It provide positive outcomes to us by improving self directed learners skills like motivation, persistent, independent, self disciplined, self confident and goal oriented. Challenges for the learner have no external validation for content or assessment since the individual is in charge of all aspects of learning from deciding what should be learned to the methods and resources used to the evaluation of the success of the effort. In peer groups children can learn e.g. social skills and empathy. Early peer group working help children to learn how to negotiate and relate to others. They learn from peers how to cooperate and socialize according to group norms and group-sanctioned modes of behavior. The peer group can can influence -in positive and negative way- for the children's values, knows, wears, eats, and learns. The extent of this influence, however, depends on other situational constraints, such as the age and personality of children and the nature of the group. A peer group is the powerful way to learn. What matters, however, is that an educator understands what in a peer group can learn and how to make the best results by using it as a learning method.

\section{GAME BASED LEARNING AND GAMIFICATION}

For games classification have been used various taxonomies which have been constructed in order to categorize different types of games [9]. Caillois' classification of games into the four categories of agon, alea, mimicry and ilinx is based on the central characteristic of the game under consideration. Some games, such as football and chess, involve skill and competition (agon), while others, for example the games of dice, are based on chance (alea). There are also games in which the role of simulation (mimicry) or vertigo (ilinx) is dominant. The last mentioned type refers to games, in which "one produces in oneself, by a rapid whirling or falling movement, a state of dizziness and disorder" [10].

Some of the board games have been planned especially for pedagogical or educational purposes [11]. The term Game Based Learning (GBL) can be defined as a framework of pedagogy which involves making use of a sport or game to pit the students against each other or themselves in order to make the learning procedure more effective, invigorating and enjoyable [12]. The elements of GBL include one or more fantasy characters, storyline, role-plays, definitive rules and regulations, winning and losing, rewards etc. This deviates the student's attention from the fear of being judged at learning or study and increases their overall performance by providing a competitive yet relaxed environment. These activities not only teaches a particular concept at which the game is focused at but also inculcates a sense of honesty and makes them understand the value of fair play.

If we analyze the following statement given by Prensky, we infer that the importance of a storyline in the learning procedure. The statement gives an example of a game based learning trick in which the kids are able to memorize about 100 Pokémon characters just with the help of a storyline provided in a televised cartoon series.

"There is no reason that a generation that can memorize over 100 Pokémon characters with all their characteristics, history and evolution can't learn the names, populations, capitals and relationships of all the 101 nations in the world" [13].

With the help of various simulations performed on students, it has been concludes that they prefer narrative or storyline driven adventure game and strategy game to the other kinds of games. It has also been concluded that the most important aspects while choosing a game are logic, memory, visualization, and problem-solving. [14] So, a game designed for a particular learning procedure much focus of the above mentioned ingredients. Through various research activities, it has been proved evidently that the process of gamification increases user engagement, goal commitment, service profitability and the plays and important factor in the overall betterment of various behavioral outcomes [15]. Even before getting this evidentiary data, this process and its impact on the human behavior 
gained a lot of attention in the corporate world. Many companies have time and again launched games or application which helped their employees to perform better [16].

In the design of the game, the idea was to take into account how educational games can best be utilized in children's learning. Also, a lot of emphasis has to be laid on making the game portable and easy to play for every child would the globe. The game has to economical and cost-efficient yet sturdy and durable so that it could last longer. Finally, a separate digital platform has to be created which would act as an assistant to the game and eliminate the requirement of an external supervision during the time the game is being played.

\section{RESEARCH GOALS}

The research goal of this game design process was to find out if Lego Therapy game can be further developed into a new game applying user centric research methods. We also wanted to know how the gamification works with sociocultural learning theory and if there is a possibility to add digital elements to the game.

\section{RESEARCH METHODS}

According to [17] the gathering and analyzing of user data is divided in to separate steps. At the beginning the designer has his/her own knowledge, estimates and presumptions about the subject. The second step is gathering the user information using various methods, for example observations and interviews. After this follows usability testing, analyzing artefacts and testing of created models and prototypes. The final step is searching for and analyzing published data and information.

In this study, two groups of children playing the Lego therapy game were observed and videotaped in Jharsuguda India, and then the recorded videos were shown to two groups of IT students in KIIT University in Bhubaneswar India. Lego therapy is a game originally designed to teach autistic children peer group skills. The main idea of the game is to play it in a group of three children. They are building with Legos together according to a pre-given task. Children must act together, and no one can perform the task without the help of the others. Players are given three roles. One is a supplier who delivers the right blocks to the builder, who builds the actual structure. One of the player is in the engineer's role. The engineer designs and decides how the structure is built. The roles are cycled between tasks, so that everybody gets a chance to be an engineer, a builder and a supplier. The role of an adult is not to interfere too much in the game session. Adults can remind the children about the game rules and about staying at their given roles. Adults can intervene and support positive interactions, provide prompts to keep the children on track and suggest compromises so that the game can proceed fluently. If two of the children are in a conflict, adults have to interfere and help the children to settle their problem. [18]

\section{$6 \quad$ DATA ANALYSIS}

The process started with inception of a Finnish-Indian consortium project titled FINDIgATE. During October 2016, this project started with three Indian Higher Educational Institutes (IIT Kanpur, Loyola University and KIIT University) and two Finnish HEI (Laurea University and Turku University). Under this FINDIgATE project, about 10 Finnish students and three teachers visited India during $10^{\text {th }}$ January $-23^{\text {rd }}$ January. From the group, one teacher and three students worked with the students of KIIT IEEE. During January 2017 data was gathered for the game development together with Indian students from KIIT University in Bhubaneswar, Jharsuguda and neighboring towns and villages.

The following figure gives a diagrammatic representation of the process which was adopted while 
performing the data collection and analysis procedure. It starts with Lego therapy session and a video that was made containing the recording of the game. This video was instrumental for the future steps as based on its analysis the conclusions were devised. Next, the conclusion was the base for the design process of the game. Based on the group interview session, ideas were also proposed for creating a digital platform which will add portability and scalability to the game. Finally, a prototype digital platform was developed based on cumulative data, findings, analysis and ideas.

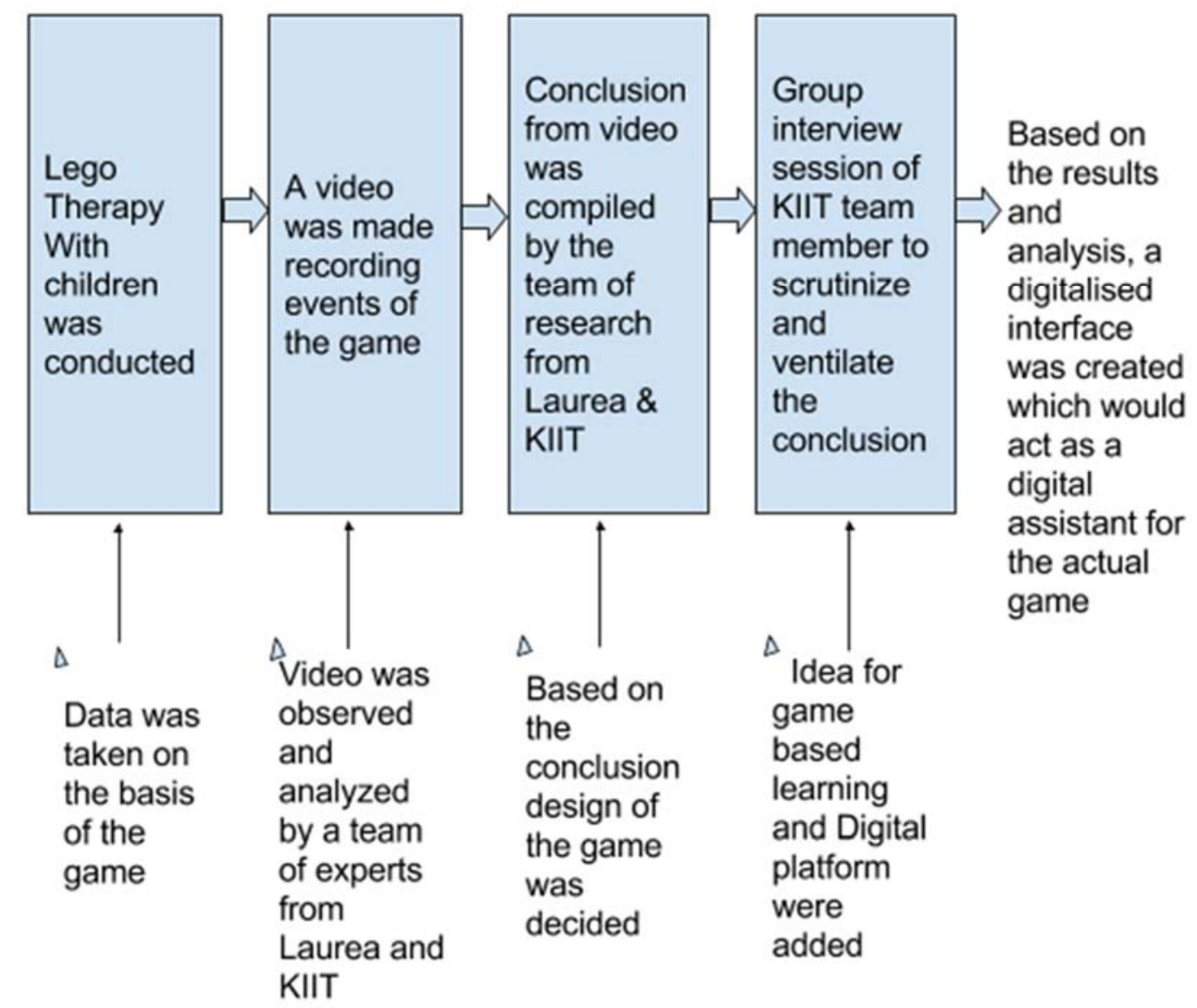

Figure 1: The process of the Game \& Interface Development

Design process of the game followed Hyysalo's [17] user-centric methods. As a starting point were the researcher's assumptions about how children will learn to use Legos in play, because they had never seen Legos before, and how the Lego therapy method would work in a different cultural context. Then followed the usability testing that consisted of the actual game play sessions that were filmed. There were two sessions, one for three boys 12-13 years old and one for girls also 12-13 years old. Videos were analyzed and then the KIIT university students watched the videos and wrote down some ideas how the game should be further developed. Based on the new ideas, a group interview was conducted for the KIIT IT-students. Based on the ideas that came up from the interview and the analyses of the researchers, future ideas for the game and smart phone application prototypes were developed.

The starting point of the game design was Lego Therapy originally developed by Daniel LeGoss in the United States. Its main idea is to teach autistic children peer group skills [18]. In our Lego Therapy session a group of three children were assigned the roles of an engineer, a builder and a supplier. The given task of building a structure was to build a park for children. We videotaped two sessions in India, one with girls aged 12-13 years old, and one with boys 12-13 years old. I had an interpreter, because the children did not speak English. The children had never seen Legos before, so we showed them 
briefly how they worked. After the game session we found out that the game also worked well in a different culture, and that the game will work in a global context.

After the game session we had about one and half hours of video material. In the videos we spotted the same kind of structure in both of the sessions. At first we assigned the roles. The engineer was the one who would design the structure, builder was the one who would build it and supplier the one who would deliver the right blocks to the builder. Then the groups started to negotiate how and with which blocks they wanted to build. Then began the active building time that lasted $10-15$ minutes. After that the building slowed down, and in both groups the roles were diverted. Sometimes all of the children were actively building or delivering blocks to the construction. Comparing boys' and girls' game sessions we did not spot any significant differences. We made shortened versions of both of the videos that showed the different phases of the process. Shortened videos were approximately ten minutes long and we added English subtitles to them, as the children were speaking their native language. The video was then shown to the KIIT University students. Then the students evaluated and analyzed the videos and answered the questions:

1. How the children work in a peer group and what kinds of learning can be seen in these peer groups?

2. What is necessary to maintain in the game?

3. How to improve the gamification segment of the Lego Therapy game?

4. What kind of digital elements can be added in the game?

The group interview was held with KIIT students to see what interviewees perceived in the videos and what the next step of the game development should be. The interview was basically a brainstorming session. In conclusion we came up with an idea of a free internet platform, where you can get the game manual and download different kinds of applications to the game.

In the new game, the group will still be of three players and the roles will be kept so that no one can build the structure alone and will have to work together. There would be a lighter version of the webpage for those who have older computers and software, and a more sophisticated version for those who have new and more effective systems. Also the building blocks could be self-made from the materials easy to find anywhere in the world. We came up an idea of using matches, ice-cream sticks etc. as Legos are too expensive and hard to find in poor countries. We came up with an idea that if the blocks were marked the computer will recognize them in different materials, and that is how we could add augmented reality into the game where more technology is available.

\section{$7 \quad$ PROTOTYPE TESTING}

During the preliminary processing of this venture, based on the experiments performed and data collected it was evident that game would need a facet of it's to be available in a digital format. Further, during the analysis process of the data and findings the need of digital interface was considered indispensable. Hence, it was decided that a certain facet of this game would be available in the form of a portable, easy to use and flexible digital format. The best fit for all the above requirements was a Mobile Application based on Android platform. The stratagem was to devise an interface that would not contain the game in itself but would act as an assistant, for the game to be smoothly played. This mobile assistant app for the game would contain essential information like the rules of the game. Since, the application is developed using Android Studio, it is very secure yet portable. It has the capacity of run on any mobile, tablet, phablet etc. just by installing the fostered APK file. Alternatively, the application can also be stored on the "Google Play Store" from where it can be directly downloaded and installed on any mobile device. There are myriad advantages of this interface. This can act as an assistant using which children can play the game in an unsupervised environment since this interface takes care of rules, time duration and all the other facets for which the children would require an adult supervision. Also, this application augments the scalability of the game as it can ensure that the game can be played 
by multiple set of children in real time.

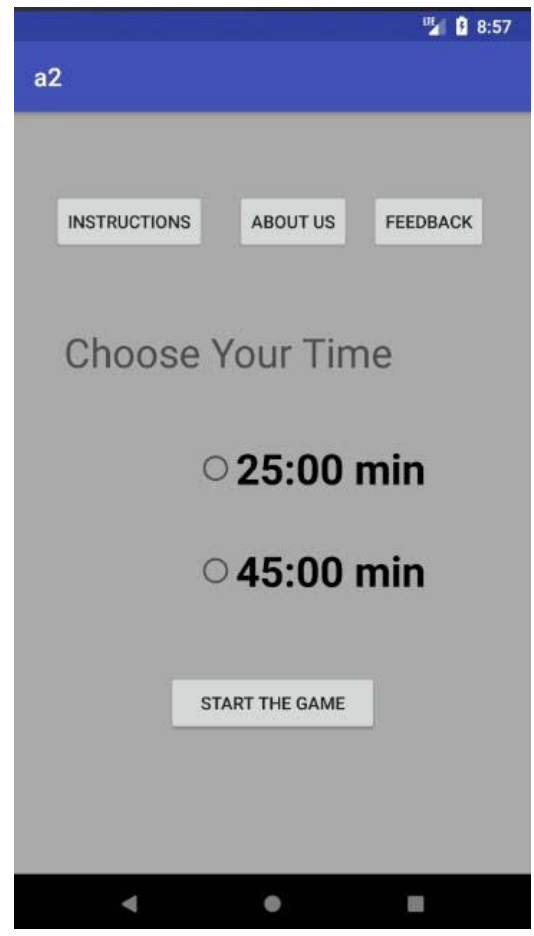

Figure 2: Interface for game (choice of duration)

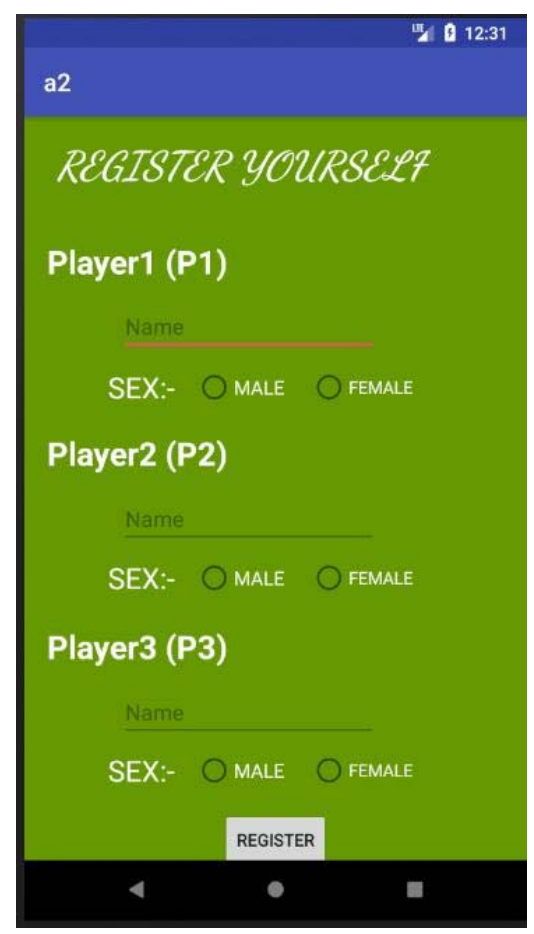

Figure 3: Interface for game (choice of players)

Now, if we look at the different screenshots of the interface, we will find that this application takes care of multiple strands and aspects of the game. In Figure 2. the student can choose the time duration they wish to spend on the game. The inbuilt stopwatch will take care of the time duration and alert the children in case of expiration of time. Next, in Figure 4. the children can register themselves on the interface. Based on the information, their profile will be created which will be further used in choosing the role. In Figure 3. there is information provided on the different role this game has to offer. For, the prototype testing we have used the roles given in a regular Lego Therapy game, but it can be change in accordance with the requirement of the game. In the last figure which is Figure 4. the children can choose their roles in accordance with the profile they created. 


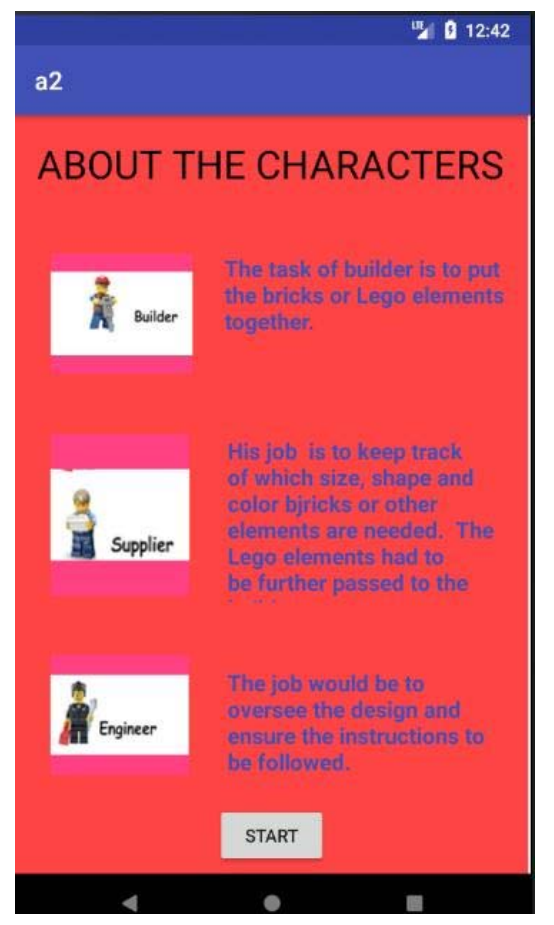

Figure 4: Interface for game (info of roles)
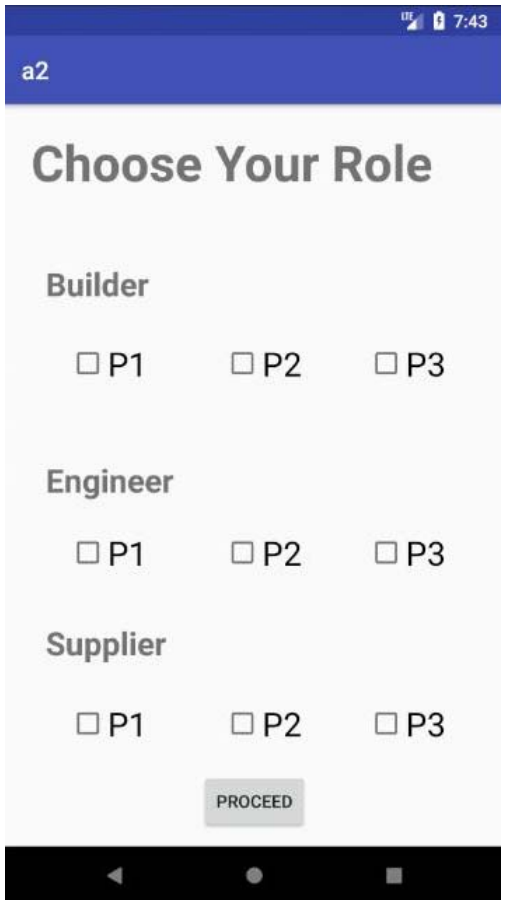

Figure 5: Interface for game (choice of roles)

\section{CONCLUSIONS AND FUTURE WORK}

In this article the focus was to describe a designing process of a game in multi professional and international team. In this designing process we got answers in many of our research questions. LEGO therapy game works well with children. Even when children had never seen Legos before in India. So it can be said that game works globally. The gamification and digital elements can also be added in the game. And the next step would be designing the web-pages and the basic manual of the game, explaining how to build the basic kit of the game.

Hence, based on data collected from India and Finland, a thorough analysis was done. Furthermore based on the analysis, a digitalized interface was created which would act as a digital assistant for the actual game. This interface was designed with a purpose which is to act as an assistant so that game to be played effortlessly. This mobile assistant app for the game contains essential information like the rules of the game, a timer for calculating the time left, option to create profile for the players etc.. This can act as an assistant using which children can play the game in an unsupervised environment since this interface takes care of rules, time duration and all the other facets for which the children would require an adult supervision. Also, this application augments the scalability of the game as it can ensure that the game can be played by multiple set of children in real time.

In the final construction of the game we wanted to change the Lego blocks into something which is cheap and globally available, like toothpicks, matchstick or ice-cream sticks. With a game manual you can build different basic blocks with it and use them to build structures. Then you can mark the block and computer will recognize them on the picture. Also, there would be two or three players and they would be given different roles. Idea of the roles is that no one can build the structure alone. That way it improves socio-cultural and peer group skills like self-directed learning skills and motivation, independency, self-confidence and goal orientation. The role of an adult is passive so that the socialization is not under control of adults. It is important that during the game session children are as active actors, not the adults. During the game roles and common purpose allows children to practice joint attention, turn taking, sharing, and joint problem solving and listening.

A game is paradoxical in that a child can flee from reality when it is playing the game, while it simultaneously gets to grips with reality in a more profound way through its imagination and creativity. The game would initially be created as a board taking physical elements as the game's components. 
But, further there is a huge scope for the digitalization of this game. We have analyzed the possibility of taking it online using a PHP framework platform. Also, we could create a mobile application on which will be created using Android Studio and Swift, which would be compatible with Android and iOS based devices. These platforms would help these games to reach out to a number of people without the requirement of a physical component.

\section{REFERENCES}

[1] L. Vygotsky, Mind in Society. The Development of higher psychological processes, Harvard University Press, Cambridge, 1978.

[2] A.-R., Lehtinen, "Vertaissuhteiden merkitys lapsen elämässä [Peers role in child's life]" in Puheenvuoroja lapsista ja varhaiskasvatuksesta [Speak about children and early childhood] (E. Hujala ed.), pp. 79-101, Jyväskylä: Varhaiskasvatus 90, 2001.

[3] S. Price and Y. Rogers, "Let's get physical: The learning benefits of interacting in digitally augmented physical spaces," Computers \& Education, vol 43, pp. 137-151, 2004.

[4] O. Lillemyr, F. Sobstad, K. Marder and T. Flowerday, "A Multicultural Perspective on Play and Learning in Primary School", IJEC 43, pp. 43-65, 2011.

[5] P. Marjanen and I. Mönkkönen, "Peer Group Learning During the Board Game Sessions," $5^{\text {th }}$ European Conference on Games Based Learning, The National and Kapodistrian University of Athens, pp. 388-394, 2011.

[6] C. Barbour, N. H. Barbour, P. A. Scully, Peer Group Influence. Pearson Allyn Bacon Prentice Hall, 2010.

[7] R. M. Golinkoff, K. Hirch-Pasek and D. Singer, "Why Play = Learning: A Challenge fo Parents and Educators" in K. Play =Learning. How Play Motivates and Enhances Children's Cognitive and Social-Emotional Growth (D. G. Singer, R. M. Golinkoff and K. Hirch-Pasek eds.), pp. 3-12, New York: Oxford University, 2006.

[8] P. Marjanen, J. Ahonen and L. Majoinen, "Vertaissuhteet ja yhteisöllisyys" [Peer relations and community] in Pienten piirissä [In the smalls circle] (P. Marjanen \& M. Marttila \& M. Varsa eds.), pp. 47-73, 2013, Jyväskylä: Ps-kustannus.

[9] S. Amaro, A. Viggiano, A. Di Costanzo, I. Madeo, A. Viggiano, M. Ena Baccari, E. Marchitelli, M. Raia, E. Viggiano, S. Deepak, M. Monda and B. De Luca, "A new education board-game, gives nutritional rudiments and encourages healthy eating in children: a pilot cluster randomized trial," European Journal of Pediatrics, vol 165, no. 9, pp. 630 - 635, 2006.

[10]R. Caillois, Man, play and games. University of Illinois Press, 2001.

[11] C. Dondi and M. Moretti, "A methodological proposal for learning games selection and quality assessment", British Journal of Education Technology, vol 38, no. 3, pp. 502-512, 2007.

[12] S. Vandercruysse, M. Vandewaetere and G. Clarebout, Handbook of Research on Serious Games as Educational, Business and Research Tools, Chapter: 32, IGI Global, pp.628-647, 2012.

[13] M. Bauerlein, The digital divide : arguments for and against Facebook, Google, texting, and the age of social networking. Jeremy P. Tarcher/Penguin, pp. 44-45, 2001.

[14]A. Amory,K. Naicker, J. Vincent and C. Adams, "The use of computer games as an educational tool: identification of appropriate game types and elements," British Journal of Educational Technology, vol 30, no. 4, pp 311-321, 1999.

[15] M. King, K. Kitchener, Understanding and Promoting Intellectual Growth and Critical Thinking in Adolescents and Adults. Jossey-Bass Higher and Adult Education Series and Jossey-Bass Social and Behavioral Science Series, 1994.

[16]M. Herger, "Enterprise Gamification — Sustainability examples", 2011. Retrieved from: http://www.enterprise-gamification.com.

[17] S. Hyysalo, Käyttäjätieto ja käyttäjätutkimuksen menetelmät [User information and user research methods]. Edita: Helsinki, 2006.

[18] Everything you need to Learn about Lego Therapy. The Wacky Warehouse, 2015. Retrieved from: http://thewackywarehouse.com/lego-therapy/ 